Lluis Blanch

Guillermo M. Albaiceta

\section{Sildenafil for pulmonary hypertension in ARDS: a new pleasant effect?}

Received: 12 January 2010

Accepted: 15 January 2010

Published online: 4 February 2010

(C) Copyright jointly hold by Springer and ESICM 2010

This editorial refers to the article available at: doi:10.1007/s00134-010-1754-3.

L. Blanch (凶)

Critical Care Center, Hospital de Sabadell, Corporació Sanitaria Parc Taulí, CIBER Enfermedades Respiratorias, Instituto de Salud Carlos III, Universitat Autònoma de Barcelona, Sabadell, Spain e-mail: lblanch@tauli.cat

\section{G. M. Albaiceta}

Departamento de Biología Funcional, Area de Fisiología, Servicio de Medicina Intensiva, Hospital Universitario Central de Asturias, Universidad de Oviedo, Oviedo, Spain e-mail: gmalbaiceta@gmail.com

Acute lung injury (ALI) as well as its more severe form, acute respiratory distress syndrome (ARDS), is a complication of several severe diseases characterized by alveolar spaces filled with exudates, loss of lung volume, acute severe hypoxemia, and pulmonary hypertension. The pathogenesis of ALI/ARDS also involves vasoconstriction leading to alterations in pulmonary blood flow and injury to lung microcirculation. Normal fibrinolytic mechanisms are impaired, causing procoagulant and thrombotic events in the pulmonary capillaries, and these events further impair the oxygenation of blood and excretion of carbon dioxide, progressively increasing pulmonary vascular resistance and worsening pulmonary hypertension [1]. In patients with ARDS, all the aforementioned pathophysiologic events are associated with an increased risk of death [2-4]. Pulmonary hypertension might be further aggravated because of hypoxic pulmonary vasoconstriction, which preserves gas exchange, and/ or protective mechanical ventilation with low tidal volume and moderate/high positive end-expiratory pressure (PEEP), which causes a variable degree of hypercapnia and subsequently vasoconstriction of the pulmonary vascular bed $[5,6]$. The negative effect of pulmonary hypertension is particularly important in the performance of the right ventricle (RV). Acute cor pulmonale, described as RV dilation with septal dyskinesia, impairment of left ventricle diastolic filling, and compensatory tachycardia to preserve cardiac output, occurs in $25 \%$ of patients with ALI/ARDS receiving protective mechanical ventilation [6]. In this scenario, systemic vasodilators are not usually recommended because their benefit on pulmonary circulation is achieved at the cost of further aggravation of ventilation/perfusion mismatch due to increases in intrapulmonary shunt and hypoxemia induced by the simultaneous dilation of systemic and pulmonary vessels, and might favor systemic hypotension [5, 7].

Selective modulation of pulmonary perfusion in ARDS became feasible with the introduction of nitric oxide (NO). Inhaled NO not only reduced pulmonary hypertension, thus decreasing the RV load, but also improved matching of ventilation and perfusion, thus ameliorating hypoxemia [5, 7, 8]. Similar findings were reported in physiologic investigations using aerosolized prostacyclin [7]. Interestingly, combining inhaled NO with other interventions such us PEEP and prone positioning yielded additive results on oxygenation [9]. However, a recent systematic review and meta-analysis found no survival advantage, and possible increased mortality and renal dysfunction with NO, precluding its routine use in ALI/ ARDS [10].

In this issue of Intensive Care Medicine, Cornet et al. [11] investigate the physiologic effect of a single 50-mg dose of sildenafil, a phosphodiesterase-5 inhibitor with non-urologic effects on right ventricular myocardium and 
in pulmonary artery smooth-muscle cells [12], in ten patients with ARDS. Interestingly, they found that sildenafil modestly but significantly decreased pulmonary arterial pressure and pulmonary artery occlusion pressure without improving oxygenation at the same time the shunt fraction increased. The authors correctly conclude that selective pulmonary vasodilation was not achieved since the ratio of pulmonary to systemic vascular resistance and the ratio of pulmonary to systemic arterial pressure remain unchanged, which can explain the deterioration in shunt fraction and oxygenation. However, the results of the Cornet et al.'s study [11] deserve further comment and must be interpreted with caution. First, the number of patients included is rather low, and the effects, although significant, are small in magnitude. Moreover, most of the patients had sepsis requiring treatment with vasoactive drugs. In sepsis, NO-induced vasodilation probably increases the effect of sildenafil in the systemic circulation [5]. Second, patients initially presenting with bilateral infiltrates suggestive of bilateral pneumonia were excluded from the study. One a priori argument could attribute the failure to achieve selective pulmonary vasodilation to the lack of responsiveness of sildenafil on vessels in consolidated regions; however, this argument is speculative and severely restricts the number of patients that can be treated. Third, in Cornet et al.'s study [11], the right ventricular stroke work index improved even at moderate values of pulmonary hypertension. Recent data showed that a decreased cardiac index, lower RV stroke index, and left ventricle deformation are common in ARDS, even during protective mechanical ventilation with moderate PEEP [13]. In this context, vasodilators could decrease RV systolic overload and increase both right and left ventricle performance [13, 14]. Fourth, the effects of vasodilators on gas exchange must be individualized in each case. When positive pressure ventilation or prone positioning improves functional lung recruitment, selective lung vasodilators improve oxygenation [9]. However, this is not the case in most patients with ARDS $[15,16]$. Therefore, the effect of aerosolized and/ or systemic vasodilators must be weighed against their net effect on heart, lung, and whole-body oxygenation. In other words, if a vasodilator moderately worsens oxygenation and shunt fraction but improves RV performance without marked effects on oxygen delivery to peripheral tissues in a patient with ARDS and severe pulmonary artery hypertension, it is probably safe to continue treatment under strict monitoring and clinical control.

Nowadays, sildenafil is recommended to improve pulmonary hemodynamics at rest and during exercise in COPD and to reduce pulmonary vascular resistance in severe forms of pulmonary arterial hypertension, where it has shown survival benefits $[12,17]$. Cornet et al.'s study [11] adds valuable physiologic information about the effects of a new and more specific vasodilator, sildenafil, in selected patients with ARDS. However, a literature search [5] reveals that a pulmonary vasodilator that is selective to lung vessels, does not cause impairment in hypoxic pulmonary vasoconstriction, and has no adverse effects is yet to be found. Until one is found, sildenafil should be considered experimental in the general ARDS population until well-designed clinical trials determine whether the benefits outweigh the risks, but it should also be considered potentially useful in patients with lifethreatening acute cor pulmonale and stable systemic hemodynamics.

\section{References}

1. Tomashefski JF Jr (2000) Pulmonary pathology of acute respiratory distress syndrome. Clin Chest Med 21:435-466

2. Squara P, Dhainaut JF, Artigas A, Carlet J (1998) Hemodynamic profile in severe ARDS: results of the European collaborative ARDS study. Intensive Care Med 24:1018-1028 Erratum in: Intensive Care Med 1999;25:247

3. Nuckton TJ, Alonso JA, Kallet RH, Daniel BM, Pittet JF, Eisner MD, Matthay MA (2002) Pulmonary deadspace fraction as a risk factor for death in the acute respiratory distress syndrome. N Engl J Med 346:1281-1286

4. Lucangelo U, Bernabè F, Vatua $S$, Degrassi G, Villagrà A, Fernandez R, Romero PV, Saura P, Borelli M, Blanch L (2008) Prognostic value of different dead space indices in mechanically ventilated patients with acute lung injury and ARDS. Chest 133:62-71
5. Moloney ED, Evans TW (2009) Pathophysiology and pharmacological treatment of pulmonary hypertension in acute respiratory distress syndrome. Eur Respir J 21:720-727

6. Vieillard-Baron A, Schmitt JM, Augarde R, Fellahi JL, Prin S, Page B, Beauchet A, Jardin F (2001) Acute cor pulmonale in acute respiratory distress syndrome submitted to protective ventilation: incidence, clinical implications, and prognosis. Crit Care Med 29:1551-1555

7. Kaisers U, Busch T, Deja M, Donaubauer B, Falke KJ (2003) Selective pulmonary vasodilation in acute respiratory distress syndrome. Crit Care Med 31(Suppl):S337-S342
8. Blanch L, Joseph D, Fernández R, Mas A, Martinez M, Vallés J, Diaz E, Baigorri F, Artigas A (1997) Hemodynamic and gas exchange responses to inhalation of nitric oxide in patients with the acute respiratory distress syndrome and in hypoxemic patients with chronic obstructive pulmonary disease. Intensive Care Med 23:51-57

9. Martinez M, Diaz E, Joseph D, Villagrá A, Mas A, Fernandez R, Blanch L (1999) Improvement in oxygenation by prone position and nitric oxide in patients with acute respiratory distress syndrome. Intensive Care Med 25:2936 
10. Adhikari NK, Burns KE, Friedrich JO, Granton JT, Cook DJ, Meade MO (2007) Effect of nitric oxide on oxygenation and mortality in acute lung injury: systematic review and metaanalysis. BMJ 334(7597):779

11. Cornet AD, Hofstra JJ, Swart EL, Girbes ARJ, Juffermans NP (2010) Sildenafil attenuates pulmonary arterial pressure, but does not improve oxygenation during ARDS. Intensive Care Med. doi:

10.1007/s00134-010-1754-3

12. Archer SL, Michelakis ED (2009) Phosphodiesterase type 5 inhibitors for pulmonary arterial hypertension. $\mathrm{N}$ Engl J Med 361:1864-1871
13. Mekontso Dessap A, Charron C, Devaquet J, Aboab J, Jardin F, Brochard L, Vieillard-Baron A (2009) Impact of acute hypercapnia and augmented positive end-expiratory pressure on right ventricle function in severe acute respiratory distress syndrome. Intensive Care Med 35:1850-1858

14. Rehberg S, Ertmer C, Westphal M (2009) Mechanical ventilation in patients with ARDS: is the lung's fortune the right ventricle's poison? Intensive Care Med 35:1825-1826

15. Villagrá A, Ochagavía A, Vatua $S$, Murias G, Del Mar Fernández M, Lopez Aguilar J, Fernández R, Blanch L (2002) Recruitment maneuvers during lung protective ventilation in acute respiratory distress syndrome. Am J Respir Crit Care Med 165:165-170
16. Albaiceta GM, Luyando LH, Parra D, Menendez R, Calvo J, Pedreira PR, Taboada (2005) Inspiratory vs. expiratory pressure-volume curves to set end-expiratory pressure in acute lung injury. Intensive Care Med 31:1370-1378

17. Blanco I, Gimeno E, Munoz PA, Pizarro S, Rodriguez-Roisin R, Roca J, Barbera JA (2009) Hemodynamic and gas exchange effects of sildenafil in patients with COPD and pulmonary hypertension. Am J Respir Crit Care Med [Epub ahead of print] 